\title{
Brachial Plexus Injury Secondary to Prolonged Prone Position in COVID-19 Pneumonia: Case Report
}

\author{
Rafael Poniachik ${ }^{1}$, Maximiliano Rosenkranz ${ }^{1}$, Warner Larrondo ${ }^{2}$, Juan \\ Castellaro $^{2}$, Gonzalo Diaz ${ }^{2}$ and Felipe Cichero ${ }^{2,3 *}$ \\ ${ }^{1}$ Orthopaedic Resident, Clínica Dávila, Universidad de los Andes, Santiago, Chile \\ ${ }^{2}$ Shoulder and Elbow Surgeon, Clínica Dávila, Santiago, Chile \\ ${ }^{3}$ Chief of Shoulder and Elbow Unit, Clínica Dávila, Santiago, Chile \\ *Corresponding Author: Felipe Cichero, Shoulder and Elbow Surgeon and Chief of \\ Shoulder and Elbow Unit, Clínica Dávila, Santiago, Chile.
}

Received: November 20, 2020

Published: December 10, 2020

(C) All rights are reserved by Felipe

Cichero., et al.

\begin{abstract}
Introduction: Peripheral neuropathy that compromises the brachial plexus have multiple causes. The prone position used in the management of patients with acute distress respiratory syndrome secondary to COVID-19 infection could cause injury to the brachial plexus.

Case Report: We report the case of a 62 year-old man who presented severe shoulder dysfunction after been managed for 7 days in prone position while receiving invasive mechanical ventilation in an intensive care unit. The patient was managed with neurorehabilitation, oral vitamin B complex and pregabalin with progressive but slow progress.

Discussion: The SARS-CoV-2 infection physiopathology on the peripheral nerve system is still not fully understood. Patients in the intensive care unit are susceptible to develop injuries to the brachial plexus mostly caused by the position of upper extremities. Prolonged use of prone position in patients with acute distress respiratory syndrome managed with invasive mechanical ventilation could cause injury to the brachial plexus. We stress the importance of actively looking for these injuries and take all the measures to prevent them.
\end{abstract}

Keywords: Prone Position; Brachial Plexus; Peripheral Nerve Injury; SARS-Cov-2 Infection

\section{Introduction}

There are multiple causes of peripheral neuropathy, in particular those that affect the brachial plexus. Main known causes include repetitive trauma, peripheric structures compression and viral neuritis [1,2]. During the current SARS-CoV-2 pandemics, many patients have developed an acute distress respiratory syndrome (ADRS), needing invasive mechanical ventilation, sometimes associated with the use of prone position [3].

Prone position is a widely described technique for the management of ADRS patients. It provides a more homogeneous pulmonary ventilation and improves the ventilation/perfusion ratio. It has been rarely used prior to the pandemic, despite its beneficial effects in ICU. This changed with the appearance of SARS COV-2, with a more extended use, in up to $11.5 \%$ of ICU patients hospitalized for COVID-19 [3,4].

Present day clinical guidelines recommend the prone position use for 12 to 16 hours per day in patients developing moderate to severe ADRS. Multiple complications, associated with ventilatory management of prone position have been described, brachial plexus injury been one of them [5].

Due to the rise of prone position use during the SARS-CoV-2 pandemics and its complications, the objective of this study is to report an infrequent complication related to prolonged prone position and the therapeutic approach used in this patient. 
Case

We report the case of a 62 year-old male patient, with no previous medical record and no previous neurological symptoms. In July 2020 he presented a severe acute distress respiratory syndrome secondary to SARS-CoV-2 pneumonia. The patient required invasive mechanical ventilation for 30 days. He was in prone position for 7 days.

He came into the office with history of 1 month of no functional active movement of the shoulder, which was associated to mild pain, $3 / 10$ in the visual analog scale (VAS). In the physical examination of the right shoulder, he presented $0^{\circ}$ of active internal rotation, external rotation, flexion, extension and abduction, strength M1 in deltoid, supraspinatus, infraspinatus and teres minor. Complete passive movement and positive impingement tests. In the elbow exam he had no active flexion-extension but a complete range of passive movement. Normal active range of motion of cervical spine was recorded. In the neurologic examination of shoulder and hand it highlights strength M2 of nerves C6 and C7 and M3 of C8 and T1.

The image study showed normal shoulder radiographs (Image 1) and the MRI had signs of suprascapular nerve neuritis and subacute degenerative changes of supraspinatus, infraspinatus and teres minor (Image 2). The study was complemented with an electromyographic study that showed a severe axonal injury in the superior trunk of the brachial plexus with signs of active axonal degeneration (Table 1).

Table 1: Right upper limb electromyography showing severe injury of brachial plexus.

\section{EMG}

\begin{tabular}{|c|c|c|c|c|c|c|c|c|c|c|c|c|c|}
\hline Side & Muscle & Nerve & Root & Ins Act & Fibs & Psw & Otro & Amp & Dur & Poly & Recrt & Int Pat & Comment \\
\hline Right & Abd Poll Brev & Median & C8-T1 & $\mathrm{Nml}$ & $\mathrm{Nml}$ & $\mathrm{Nml}$ & - & $5 \mathrm{mV}$ & $\mathrm{Nml}$ & 0 & $\mathrm{Nml}$ & Int Rico & Max \\
\hline Right & 1stDorInt & Ulnar & C8-T1 & $\mathrm{Nml}$ & $\mathrm{Nml}$ & $\mathrm{Nml}$ & - & $5 \mathrm{mV}$ & $\mathrm{Nml}$ & 0 & $\mathrm{Nml}$ & Int Rico & Max \\
\hline Right & FlexCarRad & Median & C6-7 & Aum & $\mathrm{Nml}$ & $\mathrm{Nml}$ & - & $5 \mathrm{mV}$ & $\mathrm{Nml}$ & +1 & Red & Int Med & Max \\
\hline Right & Biceps & Musculocut & C5-6 & $\mathrm{Nml}$ & $\mathrm{Nml}$ & $\mathrm{Nml}$ & - & $4 \mathrm{mV}$ & $\mathrm{Nml}$ & +1 & Red & Int pobre & $\operatorname{Max}$ \\
\hline Right & Deltoid & Axillary & C5-6 & Aum & +2 & +2 & - & Nulo & Nulo & Nulo & Nulo & Nulo & Nulo \\
\hline Right & BrachioRad & Radial & C5-6 & $\mathrm{Nml}$ & $\mathrm{Nml}$ & $\mathrm{Nml}$ & - & $4 \mathrm{mV}$ & $\mathrm{Nml}$ & +2 & Red & Int Med & Max \\
\hline Right & Ext Digitorum & Radial (Post Int) & C7-8 & $\mathrm{Nml}$ & $\mathrm{Nml}$ & $\mathrm{Nml}$ & - & $5 \mathrm{mV}$ & $\mathrm{Nml}$ & 0 & $\mathrm{Nml}$ & Interf & Max \\
\hline Right & Ext Indicis & Radial (Post Int) & C7-8 & $\mathrm{Nml}$ & $\mathrm{Nml}$ & $\mathrm{Nml}$ & - & $3 \mathrm{mV}$ & $\mathrm{Nml}$ & 0 & $\mathrm{Nml}$ & Int Rico & $\operatorname{Max}$ \\
\hline Right & Infraspinatus & SupraScap & $\mathrm{C} 5-6$ & Aum & +3 & +3 & - & Nulo & Nulo & Nulo & Nulo & Nulo & Nulo \\
\hline Right & Rhomboid Major & DorsalScap & $\mathrm{C} 5$ & $\mathrm{Nml}$ & $\mathrm{Nml}$ & $\mathrm{Nml}$ & - & $3 \mathrm{mV}$ & $\mathrm{Nml}$ & 0 & $\mathrm{Nml}$ & Int Rico & Max \\
\hline Right & C5 Parasp & Rami & $\mathrm{C} 5$ & $\mathrm{Nml}$ & $\mathrm{Nml}$ & $\mathrm{Nml}$ & - & & & & & & \\
\hline Left & Deltoid & Axillary & C5-6 & $\mathrm{Nml}$ & $\mathrm{Nml}$ & $\mathrm{Nml}$ & - & $3 \mathrm{mV}$ & $\mathrm{Nml}$ & 0 & $\mathrm{Nml}$ & Interf & Max \\
\hline Right & Supraspinatus & SupraScap & C5-6 & $\mathrm{Nml}$ & $\mathrm{Nml}$ & $\mathrm{Nml}$ & - & Gig & $\mathrm{Nml}$ & 0 & Red & Int Med & Max \\
\hline
\end{tabular}

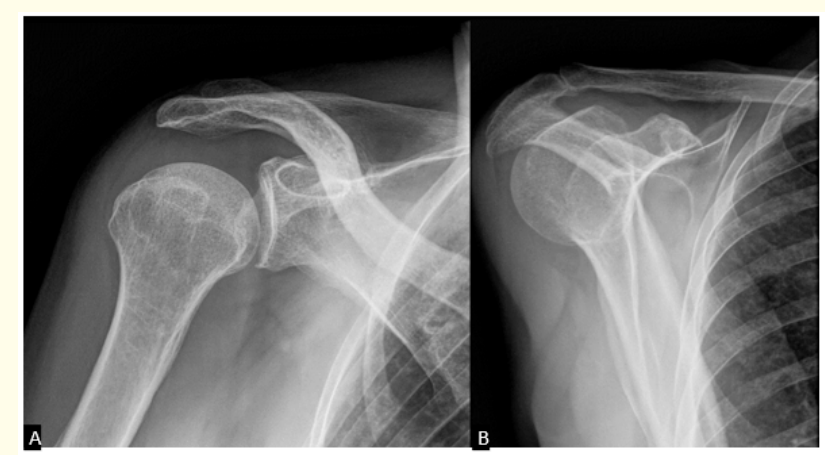

Image 1: Normal true AP (A) and scapular view (B) of the patient.

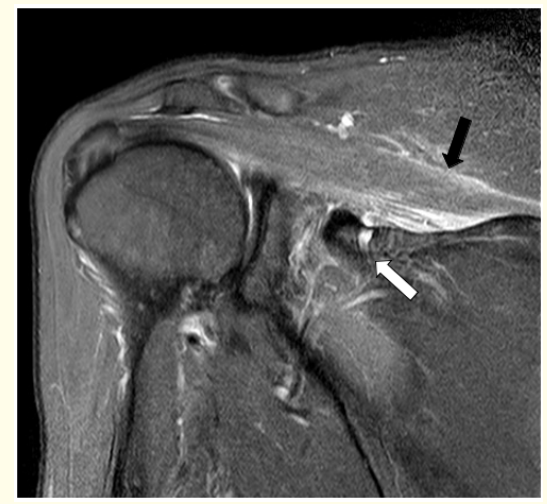

Image 2: MRI showing suprascapular neuritis (white arrow) and subacute changes of the suprascapular muscle (black arrow). 
The patient was managed with neurorehabilitation, oral vitamin B complex and pregabalin with progressive but slow progress. At 4 months, he has almost no pain, VAS $1 / 10$ and gained $30^{\circ}$ of flexion in the scapular plane, internal rotation of $15^{\circ}$ and external rotation of $10^{\circ}$. He is still undergoing neurorehabilitation.

\section{Discussion}

In the pandemic era of COVID-19, the prone position is a very frequent adjuvant to IMV in patients with ARDS. The complications associated are rare. The most frequently described complications in the literature are pressure ulcers, endotracheal tube obstruction, peripheral venous lines or central catheters during position changes. There are few reports of peripheral nerves injuries, but recently there have been some reports of brachial plexus injuries. The most frequent site is the ulnar nerve at the elbow $[5,6]$.

Peripheral nerve injuries (PNI) have been described widely in the literature, especially at the brachial plexus [6]. It is very important to suspect a brachial plexus injury in patients managed with prolonged prone position. The SARS-CoV-2 infection pathway is unknown, but it has an infection mechanism $79 \%$ similar to SARS-CoV, which invades the peripheral nerve system cells by ACE2 receptors (Angiotensin Converting Enzyme 2) or TMPRSS2 [7]. The peripheral nerve system demonstrations are anosmia, hypogeusia, Guillian-Barre syndrome and neuralgia [8], but there are no reports of direct brachial nerve injuries caused by the virus.

The intensive care unit (ICU) preventive measures are fundamental to avoid peripheric nerve injuries, which are mostly caused by the position of extremities during the prone position. The Britannic intensive care society recommends the "Swimming position" switched every 4 hours [9]. This position consists in keeping one superior extremity by the patient and the other with $80^{\circ}$ abduction and $90^{\circ}$ flexed elbow to avoid injuries. More studies are needed to evaluate the risk of brachial plexus injurie secondary to prolonged prone position and how these preventive methods decrease this risk. Neuroprotective measures do not have much backup in the literature in this kind of injuries, but vitamin complex B may have a therapeutic role in acute peripheral nerve injury because it could accelerate the nerve regeneration process $[10,11]$.

After extubation or prolonged prone position, it is recommended a neurologic evaluation and screening searching for the presence of neuropathic pain, active range of movement and sensitivity of every muscle group. Most of these symptoms revert in days or weeks, but if these symptoms persist over 3 weeks a new and complete neurologic evaluation and study with images and electromyography are indicated. The are several patterns in relation to the injury location and it can be demonstrated with an accurate physical examination [12]. Some of these patterns are:

- Superior trunk, supraclavicular: loss of shoulder and elbow motion, altered sensation or numbness over the shoulder continuing down to the thumb

- Lateral cord, infraclavicular: Loss of elbow flexion, wrist flexion/pronation and sensitivity of the outer forearm and thumb

- $\quad$ Medial cord, infraclavicular: Loss of finger abduction, adduction and a clawed hand with numbness over the inner forearm and little finger

- Posterior cord, infraclavicular: Loss of deltoid, wrist and finger extension and reduced or altered sensation from the shoulder to the back of the hand.

\section{Conclusion}

With this case we demonstrate the importance of the prevention of these injuries. If they happen, they must be directly approached. The study is indicated if the symptoms are present over 3 weeks. The COVID-19 is changing the world, how it works and the future is still unknown. The same happens with this injury, where the mechanism is not fully understood and the treatment remains unclear. The key in the management is to be suspicious about this possible scenario, a close follow-up and an aggressive multimodal treatment, including neurorehabilitation as the fundamental axis.

\section{Conflict of Interest}

The authors declare that they don't have any conflict of interest.

\section{Bibliography}

1. Mao L., et al. "Neurologic Manifestations of Hospitalized Patients With Coronavirus Disease 2019 in Wuhan, China". JAMA Neurology 77.6 (2020): 683.

2. Memon AB., et al. "Suprascapular neuropathy: A review of 87 cases". Muscle and Nerve 60.3 (2019): 250-253.

3. Alhazzani W., et al. "Surviving Sepsis Campaign: guidelines on the management of critically ill adults with Coronavirus Disease 2019 (COVID-19)". Intensive Care Medicine 46.5 (2020): 854-887. 
4. Chiumello D., et al. "Prone position in ARDS: a simple maneuver still underused". Intensive Care Medicine 44.2 (2018): 241-243.

5. Malik GR., et al. "Injury-Prone: Peripheral nerve injuries associated with prone positioning for COVID-19-related acute respiratory distress syndrome". Intensive Care and Critical Care Medicine (2020).

6. Goettler CE., et al. "Brachial plexopathy after prone positioning". Critical Care 6.6 (2002): 540.

7. Li H., et al. "Involvement of the Nervous System in SARS-CoV-2 Infection”. Neurotoxic Research 38.1 (2020): 1-7.

8. Ahmad I and Rathore FA. "Neurological manifestations and complications of COVID-19: A literature review". Journal of Clinical Neuroscience 77 (2020): 8-12.

9. Alderden J., et al. "Risk factors for pressure injuries among critical care patients: A systematic review". International Journal of Nursing Studies 71 (2017): 97-114.

10. Hussain G., et al. "Current Status of Therapeutic Approaches against Peripheral Nerve Injuries: A Detailed Story from Injury to Recovery". International Journal of Biological Sciences 16.1 (2020): 116-134.

11. Kallet RH. "A Comprehensive Review of Prone Position in ARDS". Respiratory Care 60.11 (2015): 1660-1687.

12. Simpson AI., et al. "Reducing the Risk and Impact of Brachial Plexus Injury Sustained From Prone Positioning-A Clinical Commentary". Journal of Intensive Care Medicine 35.12 (2020): 1576-1582.

\section{Assets from publication with us}

- Prompt Acknowledgement after receiving the article

- Thorough Double blinded peer review

- Rapid Publication

- Issue of Publication Certificate

- High visibility of your Published work

Website: https://www.actascientific.com/

Submit Article: https://www.actascientific.com/submission.php

Email us: editor@actascientific.com

Contact us: +919182824667 